\title{
Microsoft Windows Azure: Developing Applications for Highly Available Storage of Cloud Service
}

\author{
Pratiksha P. Nikam ${ }^{1}$, Ranjeetsingh S. Suryawanshi ${ }^{2}$ \\ ${ }^{1}$ Savitribai Phule Pune University Pune, Maharashtra, India \\ ${ }^{2}$ Professor, Savitribai Phule, Pune University, Pune, Maharashtra, India
}

\begin{abstract}
Cloud Computing is storing of data and application on remote servers and accessing them via internet rather than installing and saving them on your personal computers. As more publicly available scientific data sets become available, growing volume of this data has made it impractical to move data to desktop for analysis. These issues require a new computing paradigm-Cloud Computing. In recent years, advancement in cloud computing assure us to remove these barriers. Microsoft has huge contribution in the development of data centers for public cloud infrastructure, known as Microsoft Windows Azure, which serves the needs of scientific community. Microsoft Azure provides a variety of cloud service which enables you to select right combination that meet your needs from setting up a community website to document and discuss research findings to perform complex data analysis in scalable environment. The paper deals with a brief introduction about Microsoft Azure, its services, features and developing and deploying application on Azure cloud. It also describes the benefits offered by Azure Cloud Platform by comparing it with other Cloud Service Platform.
\end{abstract}

Keywords: Cloud computing, Microsoft Windows Azure

\section{Introduction}

Cloud Computing, also known as on-demand computing is an internet-based computing which provides information and shared resources to computer and other devices on-demand. It provides on-demand access to shared pool of configurable computing resources. It provides user enterprises with various capabilities to store and process their data in third party data centers. Its main focus is to maximize effectiveness of shared resources. Cloud Computing helps companies to avoid upfront infrastructure cost and focus on projects that differentiate their businesses instead of infrastructure. Cloud Computing has now become a highly demanded service or utility due to advantages of high computing power, cheap cost of services, high performance, scalability, accessibility as well as availability. Many companies have their own cloud service providers. Microsoft Windows Azure is a cloud computing platform released on $1^{\text {st }}$ February 2010 and created by Microsoft. It helps to build, deploy and manage application and services through a global network of Microsoft-managed data centers. The capabilities and services this platform consists of is outstanding. It provides both PaaS and IaaS services and supports many different programming language tools and frameworks including both Microsoft specific and third party software and systems. Paper provides detail introduction of Microsoft Azure and highlights all the services and features offered by Azure. It also describes the steps involved in developing and deploying applications on Azure cloud. The aim of Microsoft Azure is to build a web application that runs and stores its data in Microsoft datacenters. It store data while the applications that consume this datarun on premise (outside the public cloud). It create virtual machines to develop and test, or runSharePoint and other out-of-the-box applications. Main focus of Windows Azure is on development not the infrastructure and it develops massively scalable applications with many users.

\section{Literature Review}

By Studying different research papers, Journals related to this topic provided lot of useful information. This information consist of various cloud computing services, features and current issues related to such systems, possibility to proceed further with different solutions to the existing problems. Hence it helps a lot to enhance and overcome issues of existing methodology in future. Here are some Papers that we have referred for making literature survey.

Cloud computing is a model for enabling ubiquitous, convenient, on-demand network access to a shared pool of configurable computing resources (e.g., networks, servers, storage, applications, and services) that can be rapidly provisioned and released with minimal management effort or service provider interaction[5].Windows Azure platform readily support the computationally intensive task of orthology inference using the Roundup algorithm, in terms of computing capability and cost-effectiveness [3]. The use of inexpensive security add-on services did not provide any additional layer of security in the experiments conducted. Also the services that were configured to scan the content of our sites via FTP failed to discover the malicious files [1]. Cloud storage resources are accessible through interfaces directly exposed to the customer: a crude web-based management console, and an Application Programming Interface (API) based on RE presentational State Transfer (REST) [2]. Microsoft Window Azure is a cloud platform that provides services for developers to build, deploy and manage applications [4]. Microsoft Windows azure gained popularity in providing good cloud computing services hence is used here[6]. ClouDiA makes intelligent deployment decisions for latency-sensitive applications under heterogeneous latencies, which naturally occur in public clouds. ClouDiA is able to reduce the time-to-

\section{Volume 4 Issue 12, December 2015}




\section{International Journal of Science and Research (IJSR) \\ ISSN (Online): 2319-7064}

Index Copernicus Value (2013): 6.14 | Impact Factor (2014): 5.611

solution or response time of latencysensitive applications by $15 \%$ to $55 \%$, without any changes to application code[7]

\section{Basic System Architecture}

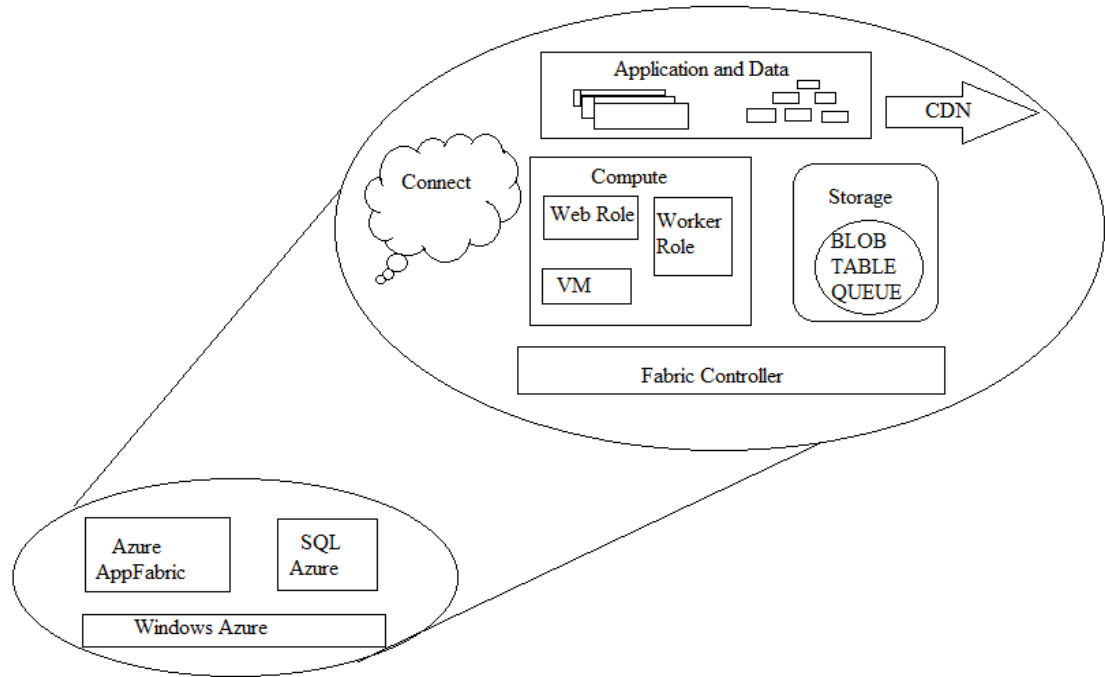

Figure 1: Microsoft Windows Azure Architecture

Windows Azure platform consist of following components:

1. Windows Azure Compute.

2. Windows Azure Storage.

3. Fabric Controller.

4. Microsoft SQL Azure

5. Windows Azure Platform AppFabric.

6. Content Delivery Network.

7. Connect.

\section{Windows Azure Compute}

The Windows Azure compute service runs applications on a Windows Server foundation. These applications can be created using any language supported by Microsoft windows Azure . Developers can use Visual Studio or other development tools, and they're free to use technologies such as ASP.NET,Windows Communication Foundation (WCF), and PHP.

Windows Azure Compute consists of:

\section{A. Web Role}

It is intended primarily for running Web-based applications. Each Web role instance has Internet Information Services (IIS) 7 pre-configured to run inside it, so creating applications using ASP.NET, or other Web technologies is straightforward. It's also possible to create applications using PHP, Java, and other non-Microsoft technologies.

\section{B. Worker Role}

These are designed to run a variety of code. A Worker role might run a simulation, for example, video processing. A web role takes the request from the application and forwards it to worker role for further processing.

\section{Virtual Machine}

A VM role is used to move some on-premises Windows Server applications to Windows Azure. When a developer gives Windows Azure an application to run, he submits configuration information along with it. Among other things, this information tells the platform how many instances of each role to run. The Windows Azure fabric controller then creates a VM for each instance, running the code for theappropriate role in each VM.

\section{Windows Azure Storage}

Windows Azure Storage consists of:

\section{A. Blob:}

It is the Binary Large Object. This is the simplest way to store data. A storage account can have one or more containers which contains on or more blobs. They store large amount of unstructured data. Blobs can be as large as 1TB and to help transfer large blobs, they are further divided into blocks.

\section{B. Tables:}

To allow applications to work with data in a more finegrained way, Windows Azure storage provides tables. These are not relational tables. But the data they contain is actually stored in set of entities with properties. A table has no defined schema; instead, properties can have various types, such as int, string, Bool, or DateTime. And rather than using SQL, an application can access a table's data using the simple query language defined by OData. A single table can be quite large, with billions of entities holding terabytes of data, and Windows Azure storage can partition it across many servers if necessary to improve performance.

\section{Queues:}

Queues are somewhat different. They allow web role instance to communicate with worker role instance. Suppose a user request to perform some task via Web page implemented by Windows Azure Web role. Web Role instance receives request and writes message on queue. The worker role then reads the message and carries out the task.

\section{Fabric Controller:}

It creates Virtual Machine and starts the application that runs in them. It also monitors all the running instances. Whenever any role instance fails, Fabric controller will generate new

\section{Volume 4 Issue 12, December 2015}




\section{International Journal of Science and Research (IJSR) \\ ISSN (Online): 2319-7064 \\ Index Copernicus Value (2013): 6.14 | Impact Factor (2014): 5.611}

role instances to maintain total number of instances required for the application.

\section{Microsoft SQL Azure}

SQL Azure consists of SQL Azure Database and SQL Azure Data Sync. SQL Azure Database provides a cloud-based database management system (DBMS). This technology lets on-premises and cloud applications store relational data on Microsoft servers in Microsoft data centers. SQL Azure is build on Microsoft SQL server. As with other cloud technologies, an organization pays only for what it uses, increasing and decreasing usage (and cost) as the organization's needs change. Using a cloud database also allows converting what would be capital expenses, such as investments in disks and DBMS software, into operating expenses.

\section{Windows Azure AppFabric:}

The goal of Windows Azure AppFabricis to provide cloudbased infrastructure. It consists of two components. Service bus and Access Control. Service Bus lets an application expose endpoints in the cloud that can be accessed by other applications, whether on-premises or in the cloud. Each exposed endpoint is assigned a URI, which clients can use to locate and access the service.Access Control provides authentication authorization services.

\section{Content Delivery Network:}

Caching frequently accessed data closer to its users speeds up access to that data. The Windows Azure CDN can do this for blobs, maintaining cached copies at sites around the world.

\section{Connect}

It's often useful for organizations to interact with cloud applications as if they were inside the organization's own firewall. Windows Azure Connect allows this, making it easier for, say, a Windows Azure application to access an on-premises database.

Table 1: Azure Services

\begin{tabular}{|c|c|}
\hline Runtime Services & Design Time Services \\
\hline $\begin{array}{c}\text { SQLserver relational } \\
\text { capabilities }\end{array}$ & $\begin{array}{c}\text { NET SDK for building app } \\
\text { azure }\end{array}$ \\
\hline $\begin{array}{c}\text { Storage sys for files \& } \\
\text { structured content }\end{array}$ & $\begin{array}{c}\text { VS Tools for packaging } \\
\text { \&deploying app to Azure }\end{array}$ \\
\hline Content Delivery Network & $\begin{array}{c}\text { Eclipse Plug-in for building } \\
\text { PHP \&Ruby app for azure }\end{array}$ \\
\hline
\end{tabular}

\section{Azure Development Life Cycle}

\section{A. Development Phase:}

1. Construct :

Application code is constructed locally on a developer's workstation. Windows Azure Application is developed in Visual Studio IDE. Visual Studio provides developers with best development platform to build Windows Azure Application.

\section{Testing:}

Once the application is developed, unit testing of code is done by the developerlocally using Visual Studio suite of testing tools such as automated unit test, web test etc. Azure development tools containsemulators for both compute and storage known as Dev Fabric and Dev storage respectively. Various test such as Smoke test, Integration test, User Acceptance tests are being carried out.

\section{B. Deployment Phase}

For any enterprise to deploy a package on Azure. They have to first provision Azure account. This can be done by Registering into Azure Portal using a Live ID and a valid debit card. This completes the registration process. After this, the user then uploads the compiled cloud packages and configuration file through Azure Management Portal.

Deployment is carried in two stages: Staging and Production. The application is first uploaded into Staging where it is tested using various test. Once the applications runs without any error in this stage then it is promoted to production which is made accessible to public usinga user friendly URL.

Table 2.Comparison of Existing Cloud Service Provider with Microsoft Windows Azure Cloud

\begin{tabular}{|c|c|c|c|}
\hline Feature & Amazon EC2 & $\begin{array}{c}\text { Google App } \\
\text { Engine }\end{array}$ & Microsoft Engine \\
\hline $\begin{array}{c}\text { Cloud Service } \\
\text { Area }\end{array}$ & IaaS & Paas & IaaS and PaaS \\
\hline $\begin{array}{c}\text { Development } \\
\text { Tools }\end{array}$ & $\begin{array}{c}\text { Only } \\
\text { provides } \\
\text { Virtual } \\
\text { Machine to } \\
\text { create images } \\
\text { of server } \\
\text { platform. }\end{array}$ & $\begin{array}{c}\text { Provides } \\
\text { editing, } \\
\text { simulation } \\
\text { and } \\
\text { deployment } \\
\text { tools. }\end{array}$ & $\begin{array}{c}\text { Provides Visual } \\
\text { Studio which is } \\
\text { one of the IDE for } \\
\text { developing cloud } \\
\text { based projects } \\
\text { using Microsoft } \\
\text { Technology }\end{array}$ \\
\hline $\begin{array}{c}\text { Platform } \\
\text { Services }\end{array}$ & $\begin{array}{c}\text { Not available } \\
\text { Google } \\
\text { Services }\end{array}$ & $\begin{array}{c}\text { Windows Azure } \\
\text { App Fabric } \\
\text { Services-Service } \\
\text { Bus Access } \\
\text { Control. }\end{array}$ \\
\hline $\begin{array}{c}\text { Programming } \\
\text { Language } \\
\text { Support }\end{array}$ & Supports & Python and & NET, JAVA, \\
oracle ,.NET & Django & $\begin{array}{c}\text { Apache, Ruby, } \\
\text { PHP, C, C++, }\end{array}$ \\
\hline
\end{tabular}

After the comparative study of Amazon, Google and Microsoft Azure we come with the conclusion that Microsoft Windows Azure provides more benefits and services and is beneficial as compared to other cloud services.

\section{Benefits}

Table 3: Benefits both IT and business may realize by adapting to Azure

\begin{tabular}{|c|c|}
\hline $\begin{array}{c}\text { IT } \\
\begin{array}{c}\text { Developers focus on building } \\
\text { functionality and business logic. They } \\
\text { don't about non-functional } \\
\text { requirements. }\end{array}\end{array}$ & $\begin{array}{c}\text { Enables Cost reduction and } \\
\text { better cost management. }\end{array}$ \\
\hline $\begin{array}{c}\text { Azure Platform manages heavy lifting } \\
\text { required for scalability and fault } \\
\text { tolerance. }\end{array}$ & $\begin{array}{c}\text { Delivers systems which are } \\
\text { more agile and responsive } \\
\text { to meet business needs. }\end{array}$ \\
\hline $\begin{array}{c}\text { Manage hardware environments and } \\
\text { software deployment. }\end{array}$ & $\begin{array}{c}\text { Help companies to innovate } \\
\text { faster and cheaply. }\end{array}$ \\
\hline $\begin{array}{c}\text { Internet scale application can be build } \\
\text { with speed and efficiency. }\end{array}$ & $\begin{array}{c}\text { Handles peaks and troughs } \\
\text { in demand without any } \\
\text { upfront investment. }\end{array}$ \\
\hline
\end{tabular}




\section{Conclusion and Future Work}

Cloud computing now creates opportunities for all researchers to find patterns or anomalies in their data even with a limited budget. Furthermore, the lower cost of storage means the research community at large can share data, promoting deeper collaboration within the community and enabling data mashups with the potential to reveal new insights. Microsoft Azure provides the necessary cloud platform to reduce not only the time to discovery, but also the cost of discovery. Now is the time to try Microsoft Azure for you and discover firsthand how easy it is to set up and go live. Future work will be related to providing security services offered by Azure.

\section{References}

[1] D. Canali, D. Balzarotti and A. Francillon, "The Role of Web Hosting Providers in Detecting Compromised Websites," International Conference on World Wide Web, pp. 177-187, 2013.

[2] E.Bocchi, M.Mellia," Cloud Storage Service Benchmarking: Methodologies and Experimentations, IEEE $3^{\text {rd }}$ International conference on Cloud Networking 2014.

[3] Kim, Insik, Jae-Yoon Jung, Todd F. DeLuca, Tristan H. Nelson, and Dennis P. Wall. "Cloud computing for comparative genomics with windows azure platform."Evolutionary bioinformatics online, Vol. 8(1), pp. 527, 2012.

[4] Neearj Mangla, Jaskirat Singh, Manpreet Singh, "Improving Performance of Web Applications Using Cloud Resources", ICRITO, $20143^{\text {rd }}$ International Conference onDOI- 10.1109/ICRITO.2014.7014765.

[5] P. Mell and T. Grance. Definition of cloud computing. Technical report, National Institute of Standard and Technology (NIST), July 2009.

[6] Ravi Shankar G et.al, "Windows Azure: A Highly Available Storage of cloud Service through Secured Channels", Volume 4, Issue 9, September 2014 ISSN: 2277 128X International Journal of Advanced Research in Computer Science and Software Engineering.

[7] T. Zou, R. Bras, M. Salles, A. Demers and J.Gehrke, "ClouDiA: a deployment advisor for public clouds," Proceedings of the 39th International Conference on Very Large Data Bases, pp. 121-132, 2012.

\section{Author Profile}

Pratiksha P. Nikam, Student of Trinity College of Engineering \& Research Pune.

Prof. Ranjeetsingh S. Suryawanshi, Faculty of Trinity College of Engineering \& Research, Pune 